\title{
Hybridization Effect on Crashworthiness Parameters of Natural Composite
}

\author{
Sabah Salim Hamza ${ }^{1,2}$, Al Emran Ismail ${ }^{1,3 *}$, M. Y. Yuhazri ${ }^{4}$, Ahmad Hamdan Ariffin ${ }^{1,5,6}$ and \\ Mohamed Thariq Hameed Sultan ${ }^{7,8,9}$
}

${ }^{1}$ Faculty of Mechanical and Manufacturing Engineering, University Tun Hussein Onn Malaysia (UTHM), Parit Raja, Malaysia, ${ }^{2} \mathrm{Al}$ Muthana Water Directorate, General Directorate of Water, Ministry of Municipalities and Public Works, Baghdad, Iraq, ${ }^{3}$ Faculty of Maritime Studies, Universiti Malaysia Terengganu, Terengganu, Malaysia, ${ }^{4}$ Faculty of Mechanical and Manufacturing Engineering Technology, Universiti Teknikal Malaysia Melaka, Melaka, Malaysia, ${ }^{5}$ Structural Integrity and Monitoring Research Group (SIMReG), Universiti Tun Hussein Onn Malaysia, Parit Raja, Malaysia, ${ }^{6}$ Center of Excellence Geopolymer and Green Technology (CeGeoGTech), Universiti Malaysia Perlis (UniMAP), Kangar, Malaysia, ${ }^{7}$ Department of Aerospace Engineering, Faculty of Engineering, Universiti Putra Malaysia, Serdang, Malaysia, ${ }^{2}$ Laboratory of Biocomposite Technology, Institute of Tropical Forestry and Forest Products (INTROP), Universiti Putra Malaysia, UPM Serdang, Malaysia, ${ }^{9}$ Aerospace Malaysia Innovation Centre (944751-A), Prime Minister's Department, MIGHT Partnership Hub, Jalan Impact, Cyberjaya, Malaysia

OPEN ACCESS

Edited by:

Andreas J. Brunner,

Swiss Federal Laboratories for Materials Science and Technology,

Switzerland

Reviewed by:

Wesley Cantwell,

Khalifa University, United Arab Emirates

Bamber Blackman, Imperial College London, United Kingdom

*Correspondence:

Al Emran Ismail emran@uthm.edu.my; al_emran@hotmail.com

Specialty section:

This article was submitted to Polymeric and Composite Materials, a section of the journal Frontiers in Materials

Received: 19 October 2020 Accepted: 07 January 2021 Published: 11 February 2021

Citation:

Salim Hamza S, Ismail AE, Yuhazri MY, Ariffin AH and Hameed Sultan MT (2021) Hybridization Effect on Crashworthiness Parameters of Natural Composite.

Front. Mater. 8:619245 doi: 10.3389/fmats.2021.619245
The use of metallic materials in automotive industry leads to increasing fuel consumption and cost, so trends are starting to use lighter and cheaper materials. In automotive applications, fibers are used in composites because they are stronger, stiffer, and lighter than bulk materials, and they can achieve higher energy absorbing compared to metallic materials. The purpose of this work is to study the potential utilization of natural fibers in the crash energy absorbing applications. The experimental procedures (the principle of a combination of manual layup and vacuum bladder technique) were applied to search the influence of utilizing jute fiber mat on crashworthiness parameters of composite materials with other kinds of fibers such as woven glass fiber reinforced epoxy composites. The study involved corrugated composite tubes with three layers of jute and hybrid glass-jute/epoxy material have been tested in uniaxial quasistatic crush conditions at the speed $10 \mathrm{~mm} / \mathrm{min}$. The results exhibit that the tube of jute fiber was somewhat lower than synthetic fibers, but the substitution of one layer of jute fiber with one layer of glass fiber resulted in an improvement in the crashworthiness parameters. As hybrid jute-glass was used, the best result was obtained, where energy absorption and specific energy absorption are improved by $17.75 \%$ and $25.122 \%$, respectively.

Keywords: hybrid composites, jute fiber, quasi-static, crashworthiness parameters, fabrication

\section{INTRODUCTION}

Synthetic fibers such as carbon and glass fibers reinforced plastics composites (FRPc) have been vastly applied in industries and transportation field due to their properties such as low density and good mechanical characteristics (Okubo et al., 2004; Summerscales et al., 2010). However, these fibers are neither recycled nor naturally decomposed; therefore, the researchers and manufactures have been trended to find natural materials as alternative due to increased ecological consciousness (Okubo et al., 2004). In recent years, focus has been on studying fibers based on natural sources. To name a few, hemp, Kenaf, flax, and jute have been well known for their mechanical properties (Summerscales et al., 2010). Apart from that, natural fibers possess lower weight, good specific strength, and lower cost, and most of all, they are available in abundance (Abosbaia et al., 2003; 
TABLE 1 | Description of composite specimens.

\begin{tabular}{lccccc}
$\begin{array}{l}\text { Type } \\
\text { of } \\
\text { tube }\end{array}$ & $\begin{array}{c}\text { No. of } \\
\text { layers }\end{array}$ & $\begin{array}{c}\text { Height, } \\
\mathbf{h} \\
\mathbf{( m m )}\end{array}$ & $\begin{array}{c}\text { Upper } \\
\text { diameter, } \\
\text { dup } \mathbf{( m m})\end{array}$ & $\begin{array}{c}\text { Lower } \\
\text { diameter, } \\
\text { dlw } \mathbf{( m m})\end{array}$ & $\begin{array}{c}\text { Number of } \\
\text { specimens } \\
\text { tested }\end{array}$ \\
\hline JCS & 3 & 100 & 56 & 44 & 5 \\
HCS & 3 & 100 & 56 & 44 & 5 \\
\hline
\end{tabular}

Mahdi et al., 2003b; Ismail et al., 2007; Lau, Said, and Yaakob 2012; Ismail and Che Abdul Aziz, 2015; Ismail, 2016; Ismail and Mohd Tobi, 2016).

In axial crushing of composites, less research on the use of natural fiber reinforced plastics has been performed. Meanwhile, carbon and glass fiber reinforced plastics are extensively investigated (Lau et al., 2012). Various shapes, geometries of structure, and kinds of failure modes that led to the different energy absorbing have been studied. According to Abosbaia et al. (2003) who have investigated the influence of segmented composites on the collapse behavior of cotton/epoxy composite structures, the filament winding method and different stacking sequences were adopted. As a result, the cotton/epoxy composite specimens showed a progressive failure under axial compression test with SEA value of $2.501 \mathrm{~kJ} / \mathrm{kg}$. Similar works were also studied in the literature by Mahdi et al. (2003a). Furthermore, a work by Ghoushji et al. (2017) tested the natural square ramie fibers/epoxy composite structures by applying various lengths. The study concluded that, with the increasing specimen length, an increase in the energy absorption capacity is produced. The maximum SEA value gained from the test was $4.841 \mathrm{~kJ} / \mathrm{kg}$. The report by Said et al. (2017) was on square-shaped kenaf/epoxy composite specimens. In their work, it was revealed that unidirectional fibers showed a better energy absorbing performance compared to the random orientation of the fibers. Besides, most of the unidirectional plies' specimens exhibited stable crushing through progressive failure and recorded the highest of $S E A$ by $22.4 \mathrm{~kJ} / \mathrm{kg}$. However, to this date, very limited researches have been done on the crashworthiness characterization of jute FRC tubes (Sivagurunathan et al., 2018b). Jute has caught a great attention to scientists and manufacturers due to its novel mechanical properties and environmentally friendly characteristics (Raghavendra et al., 2014). Besides, jute has been used in making intermediate and finishing goods such as clothing, souvenirs, and mats (Mishra \& Biswas, 2013). Although jute possesses several great mechanical properties, it is rarely used in crashworthiness studies on composite structures.

From literature review, the type of fibers used in the tests affects the crashworthiness parameters. In spite of all the above tubes crushed progressively, specific energy absorption (SEA) of natural fiber reinforced composites was relatively low compared to carbon and glass fiber reinforced plastics which for cotton, ramie, and kenaf reinforced plastics composite were at 2.501, 4.841 , and $22.400 \mathrm{~kJ} / \mathrm{kg}$, respectively. Therefore, to solve this problem, hybridization is considered the best option. The main idea is to make a balance between the high modulus fibers such as synthetic fibers that contribute to load bearing and stiffens and the materials with low modulus fibers such as natural fibers, which contribute to damage tolerance. This approach makes a balancing in stiffness, toughness, and

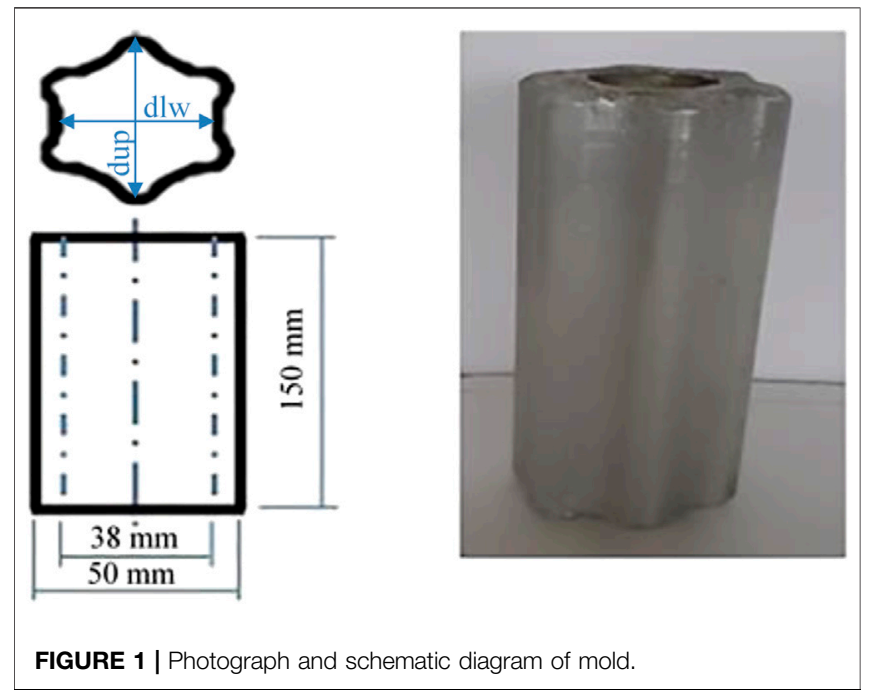

strength with weight reduction. Then get a new specimen with best specification compared to both materials, which can absorb high EA. Through the synergistic effect of the fibers, a new material can be obtained with characteristics that differ from both of them and an improvement in the ability of the structure to absorb energy and the behavior of crashing during axial loading (Reddy et al., 2016).

In the current study, the use of bidirectional jute and hybrid glassjute fiber in three layers was investigated to determine which is the most effective configuration in terms of SEA. Moreover, since many works have proven that tulip trigger (Palanivelu et al., 2010; Palanivelu et al., 2011; Sivagurunathan et al., 2018a) and corrugated tubes (Abdewi et al., 2008; Lau et al., 2012; Al-Qrimli et al., 2015) have highest effect on crashworthiness parameters values, they have been determined as constant.

\section{EXPERIMENTAL PROCEDURE}

\section{Specimen Geometry}

Two kinds of specimens have been studied, hollow corrugated composite tubes. The two specimens were fabricated one by pure jute/epoxy and the other by hybrid jute-glass/epoxy. All specimens were made in the same conditions with a constant number of laminate layers equal to three. Details on the height (h), upper diameter (dup), and lower diameter (dlw) are given in Table 1 (please refer to Figure 1 for the notations utilized).

\section{Materials and Configuration}

Two kind of fibers were used in present work: the woven jute (plain weave, $1.44 \mathrm{~g} / \mathrm{cm}^{3}$ ) was procured from Innovative Pultrusion Sdn. Bhd, Seremban, Malaysia, while woven glass fibers (plain weave, $2.55 \mathrm{~g} / \mathrm{cm}^{3}$ ) were provided by University Tun Hussein Onn Malaysia (UTHM). Both kinds of fibers come in mat form with bidirectional fibers orientation of $0^{\circ}$ and $90^{\circ}$.

In order to strengthen the fibers reinforcement, a resin matrix was utilized in current work. The catalyst used was a combination of Auto-Fix 1710-A epoxy resin and Auto-Fix 1345-B as hardener. The 
epoxy and hardener were supplied by Chemibond Corporation, Malaysia.

Two configurations were manufactured and tested in the same conditions in order to provide a means of comparison.

\section{Preparation of the Mandrel}

After the materials were prepared, the second phase began with the preparation of the mandrels. Corrugated geometry of mandrel has been used, which was made from aluminum metal in the workshop by CNC machine with height of $150 \mathrm{~mm}$ and external diameter of $50 \mathrm{~mm}$ as depicted in Figure 1. The mandrel was then wrapped by a layer of plastic to prevent the epoxy from sticking to the mandrel, which might affect the specimens through extraction.

\section{Fabrication Process}

The novel principle of a combination of manual layup and vacuum bladder technique was employed. Through the compression vacuum-bagging technique is used in present work. "Vacuumbagging" is an advanced composite molding technique that used a pump to draw a vacuum over the composite laminate, allowing even atmospheric pressure to compact the laminate against the mold face and improve its performance. However, both specimens were fabricated with the fiber volume fraction of $60 \%$ (Shibata, Cao, and Fukumoto 2005). For facilitating the removal of the specimen from the mold, wiping the releasing agent on the surface of the mandrel was applied. The reinforced materials were trimmed to the proper size of the mold and then weighed for equivalent epoxy use of the layers. Epoxy and hardener were mixed at ratio 1:1 as per the supplier's instructions by an electric mixer. The electric mixer was used in order to prevent air bubble formation in a mixture. The epoxy resin was poured and spread by using a brush onto the jute layers and then wrapping the fibers around the mandrel. A steel roller was moved over each jute-epoxy layer under a mild press down to dispose air bubbles from the laminate and to obtain the required thickness. The peel/release ply, release film, and bleeder film were cut as per the mold size and placed on the surface of layers. The whole specimen was sealed by using a vacuum bag under constant vacuum pressure of 6 bars. Under vacuum, air bubbles were eliminated and the resin was distributed into composite laminate equally. The fabricated specimens were left to cure for $24 \mathrm{~h}$ at laboratory temperature $\left(30^{\circ} \mathrm{C} \pm 2 \%\right)$. After that, the specimens were extracted from the vacuum-bagging and mold. The postcuring was carried out by placing samples into a heat oven at $60^{\circ} \mathrm{C}$ for $8 \mathrm{~h}$ and $100^{\circ} \mathrm{C}$ for $4 \mathrm{~h}$. Finally, all tubes were cut into the required specimen size with a height of $100 \mathrm{~mm}$ by using bench saw; a tulip trigger was done by using an angle grinder for each one. This process was repeated four times for each specimen.

\section{Weighing and Labeling}

The specimens were weighed, and then nominations were used for the specimens before and after the crush to classify them, where $(J)$ represents jute fibers mat, the $(G)$ represents the woven glass fibers, and $(\mathrm{H})$ represents hybrid fiber of (2 Jute +1 Glass). As only one epoxy form was used, the matrix (epoxy) was not symbolized. Two kinds of composite constituents' specimens have been studied, jute composite specimens (JCS) and hybrid composite specimens (HCS).

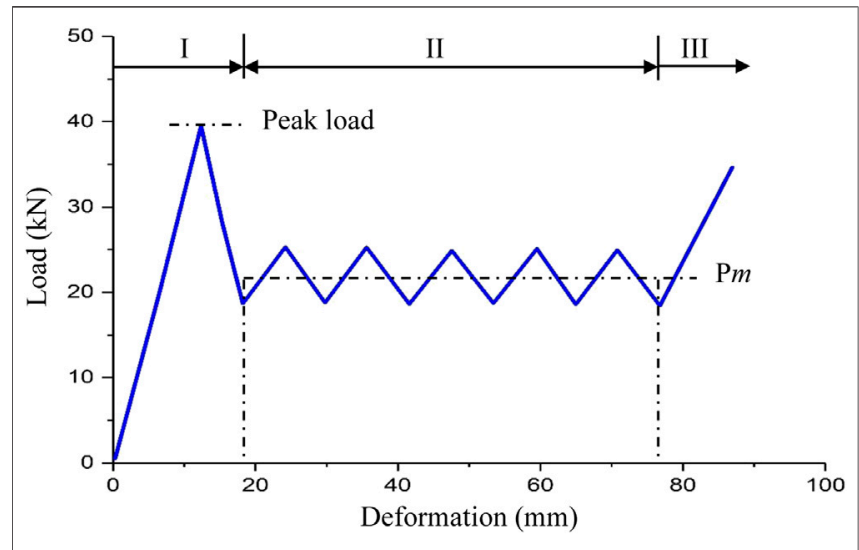

FIGURE 2 | Typical force-displacement graph (Rabiee and Ghasemnejad, 2017).

\section{Testing Procedure}

The samples tests were carried out by applying quasi-static uniaxial compression forces using an Autograph AG-X plus Shimadzu Universal Testing System with a loading of $100 \mathrm{kN}$ at UTeM University, Melaka, Malaysia. The measurements were done based on ASTM: D7336M-16 with a stroke of $80 \mathrm{~mm}$. The speed of the crosshead was $10 \mathrm{~mm} / \mathrm{min}$. Each specimen was placed on the lower fixed platen and the parallel platen started to crush axially. To ensure that the collected findings are consistent and accurate, five replicate tests were done for each configuration. Load and displacement test data were obtained by the automatic acquisition system to determine the crashworthiness parameters and absorb the energy of the designed specimens.

\section{CHARACTERIZATION METHODS}

\section{Crashworthiness Parameters}

Crashworthiness is an important key parameter that must be taken into consideration when assessing the safety factor of structures. Besides, the collision energy is absorbed in a controlled failure mechanism by the gradual decay of the specimen under a compressive load. However, different indicators are available to assess the absorbing energy and crush characteristics of various structures (Mahdi and Sebaey, 2014b). These indicators will be computed and analyzed mathematically based on a load- $(\mathrm{kN})$ displacement (mm) which is illustrated in Figure 2:

1. The peak load is the maximum sustained load that a particular specimen can endure before it undergoes failure during the elastic phase, which can be determined directly from the loaddisplacement diagram. Besides, peak load also determines how long the specimen can withstand before it completely fails.

2. The energy absorbing (EA) of a structure or body refers to its capability to do the work done and resistance to an external load. Within this context of the definition, the high-energy structure will be capable of deforming widely to dissipate the impact load (Sun et al., 2017). Total absorbed energy, EA, 
represents the area underneath the load-deformation diagram until the compaction region. It can be computed as follows:

$$
E A=\int_{0}^{\delta} P d \delta,
$$

where $(\delta)$ represent the displacement distance $(\mathrm{mm})$ and $p$ is the axial average load.

3. The mean load rate is one of the important indicators by which the energy absorption measuring of the tested specimen can be determined. It plays a main role in defining the characteristics of crashworthiness because the crushing efficiency represents the ratio of the mean load to the maximum peak load and therefore it is closely related to the increase or decrease of acceleration that will face the vehicle's passengers in a collision event (Roslan et al., 2017). $\mathrm{P}_{m}$ can be computed by total energy absorption divided by deformation distance as follows:

$$
P_{m}=\frac{E A}{\delta}
$$

4. The specific energy absorption (SEA) is due to the difference in material and weight of each specimen used in study. The evaluation through total energy absorption to determine the structure's capability to dissipate energy stably may be misleading. Therefore, to make a more realistic comparison among the geometric specimens, it is based on the SEA (Mahdi and Sebaey, 2014b). SEA can be computed as follows:

$$
S E A=\frac{E A}{W}
$$

where (W) represent crushed weight of tested specimen.

5. Crush efficiency $\left(\mathrm{n}_{\mathrm{c}}\right)$ is another significant indicator that needs to be taken into consideration in assessing the energy dissipation performance of the designed structure. It is calculated mathematically by dividing the average load over the maximum peak load, which is usually from zero to one. Therefore, the closer the efficiency is to a unit, it indicates that the performance is close to the ideal value. Thus it leads to an increase in deceleration during the collision event and increases safety probability to the object (Boria, Scattina and Belingardi 2018).

$$
\eta_{c}=\frac{P m}{P \max } .
$$

\section{RESULTS AND DISCUSSION}

\section{Load vs. Deformation Response and Failure Mode}

Details of crashworthiness characteristics of the composite specimen include the peak load $\left(P_{\max }\right)$, mean deformation

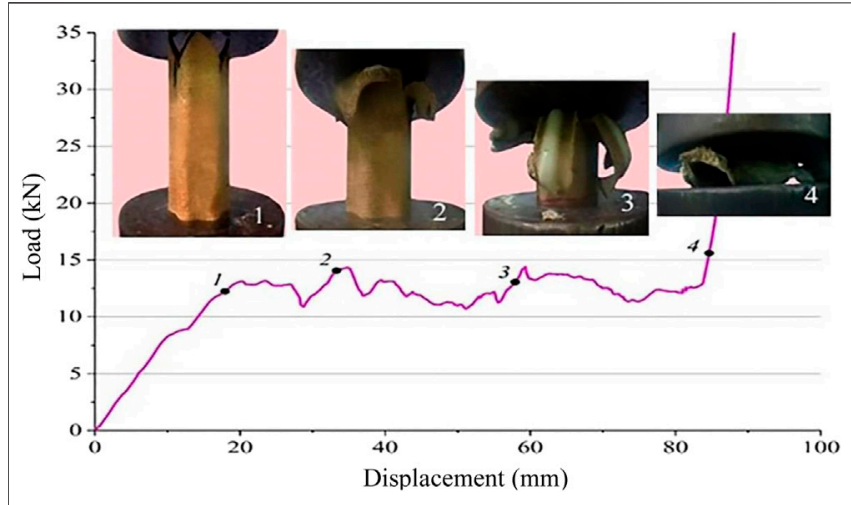

FIGURE 3 | Representative load vs. displacement and collapse history of corrugated JCS with three layers.

load $\left(P_{m}\right)$, energy absorption $(E A)$, specific energy absorption $(S E A)$, and crushing efficiency $\left(\eta_{c}\right)$ (Roslan et al., 2017).

From the test results, the typical force-displacement graph can be distributed into three regions as in Figure 2 (Abdewi et al., 2006). The first region (I) represents the precrushing phase, in which the load $(p)$ increases dramatically and reaches an initial maximum load $P_{\max }$ within elastic failure behavior before dropping. In the second region (II), the load fluctuated about a mean load over the crushing process in the plastic failure region and it is associated with the postcrushing phase. The forcedisplacement graph exhibited the $P_{\max }, P_{m}$, and the displacement of the final failure. In the third region (III), known as the compaction phase, the load increases drastically and nonlinearly because of debris accumulations at the end of the tube. This region was not taken into account due to its small absorbing energy compared with the postcrushing region. The tests results have been mentioned in detail in the next section. These findings are matching with McGregor et al. (2016) and Said et al. (2017).

\section{Crushing Behavior of JCS}

The load vs. displacement diagram and deformation trace for corrugated JCS with three layers are shown in Figure 3. In the precrushing phase, the load escalated nonlinearly up to attaining an initial peak load of $13.101 \mathrm{kN}$ at $20.277 \mathrm{~mm}$ displacement and then started to fluctuate and progressively around mean load with the stable manner during the postcrushing phase. The longitudinal cracks were noted only at the curvature locations from the top and along its length due to the stress concentration at the curvature of the corrugated surface composite pattern. A splaying manner is characterized by very long cracks. The lamina bundles were not fractured as they underwent bending deformation. At this postcrushing phase, the maximum peak load was $14.399 \mathrm{kN}$ at $59.323 \mathrm{~mm}$ displacement. This was owing to hoop constraint resulting from the axial crack opening along its length of the specimen wall due to the concentration of stress at the curvature of the corrugated composite specimen. Besides, geometry plays a serious role in the influence on the failure mechanism. As a result, the tube contributed a substantial amount of crushing energy absorption (mode I) showing 


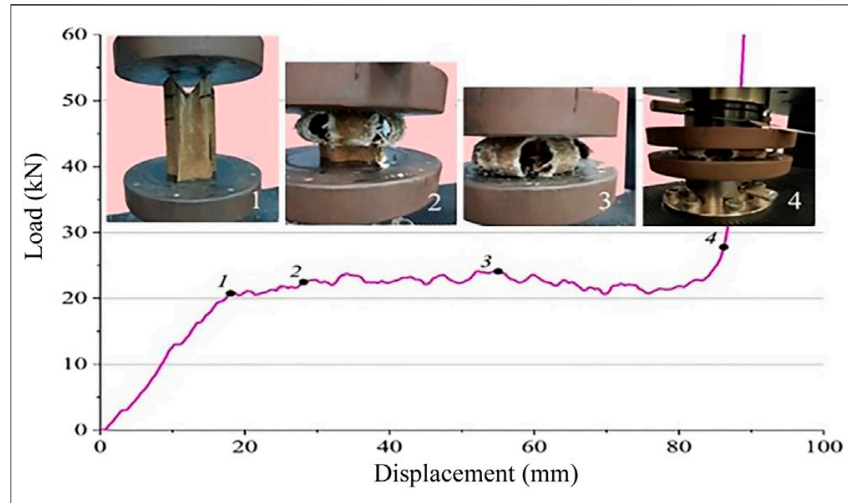

FIGURE 4 | Representative load vs. displacement and collapse history of the corrugated HCS with three layers.

steady and progressive deformation throughout the test. When the load exceeded $80 \mathrm{~mm}$ displacement, it began to increase dramatically due to crushed materials that accumulated during axial loading applying as it reached the compaction phase. The principal energy absorption was through cracks developed along the axial specimen wall, bending of lamina bundles, and contribution of friction effect between the steel platen surface, fronds, adjacent lamina, debris wedge, and delamination. This phenomenon is in the same line as stated by Lau et al. (2012) and Rabiee and Ghasemnejad (2017).

\section{Crushing Behavior of HCS}

Typical load vs. displacement graph and collapse history of the corrugated hybrid composite specimen with three layers are depicted in Figure 4. In the first phase, the load increases nonlinearly up to attaining an initial peak value of $20.838 \mathrm{kN}$ at $18.358 \mathrm{~mm}$ displacement, which represents the end of the tube trigger. However, during a short distance of displacement, stable fluctuating loads were established around the mean load as plotted in bottom of figure mentioned above. This was indicating the lamina-splaying mode intralaminar, long interlaminar, and parallel to the fibers bundle slits as illustrated in Figure 4 (Top). These mechanisms led to the formation of fronds that spread outwards and inwards continuously. On the other hand, friction and intra/interlaminar fractures control the energy absorbing amount of bundle bending manner. During the postcrushing phase, the maximum load recorded $24.151 \mathrm{kN}$ at $54.546 \mathrm{~mm}$ displacement. It is noted that the lamina bending deformation mode contributes to the largest energy absorption compared to other modes. This large energy absorption (EA) was caused by a higher collapse area and thus a bigger potential to dissipate higher energy by splaying or bending accompanied with peel-off effects resulting from friction between the platen and specimen wall interface (refer to Figure 4, top No. 6).

\section{Hybridization Influence on Peak Load, Mean Load, and Crush Efficiency}

Due to the strong correlation among peak load $\left(P_{\max }\right)$, average load $\left(P_{m}\right)$, and crushing efficiency $\left(n_{c}\right)$ and their effect on the load

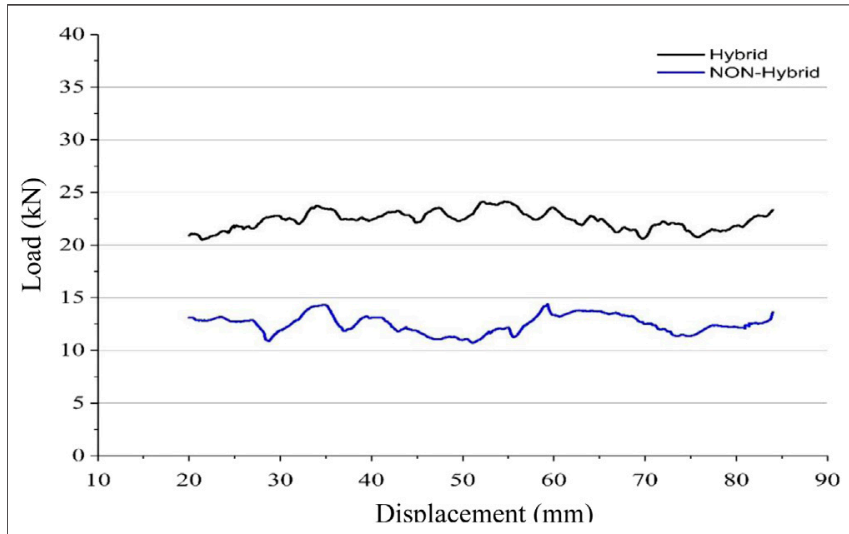

FIGURE 5 | A comparison of sustained load between hybrid and nonhybrid composite specimens at postcrushing stage.

TABLE 2 | The mean crashworthiness parameter values of the hybrid and nonhybrid specimens.

\begin{tabular}{lcccccc} 
Sample & $\begin{array}{c}\boldsymbol{P}_{\text {max }}, \\
\mathbf{k N}\end{array}$ & $\begin{array}{c}\boldsymbol{P}_{\boldsymbol{m}}, \\
\mathbf{k N}\end{array}$ & $\begin{array}{c}\text { Crushed } \\
\text { mass, } \mathbf{g}\end{array}$ & $\boldsymbol{E A}, \mathbf{J}$ & $\begin{array}{c}\text { SEA, } \\
\mathbf{J} / \mathbf{g}\end{array}$ & $\eta_{\mathbf{c}}$ \% \\
\hline JCS & 14.40 & 11.21 & 29 & 896.63 & 30.92 & 77.8 \\
HCS & 24.15 & 19.61 & 35 & 1568.71 & 44.82 & 81.2
\end{tabular}

curve behavior, it is advisable to discuss all these parameters together. On the other hand, a growth in acceleration is caused by peak load value $\left(P_{\max }\right)$ exceeding the average load $\left(P_{m}\right)$, thus leading to structural damage or reducing passengers' safety factor. However, to demonstrate the hybrid influence on the $P_{\max }$ value in this section, a comparison must be made between the hybrid and nonhybrid samples tested under the same conditions. Figure 5 shows $P_{\max }$ behavior under quasi-static loading for hybrid and nonhybrid specimens. This comparison showed that the hybridization by replacing one layer of jute mat with one layer of glass achieved a higher peak load compared to the nonhybrid jute specimen. From the results obtained, it is observed that fiber's content of specimen has effectively influenced the maximum peak load under quasi-static loading condition. The main reason for the occurrence of this phenomenon is attributed to the high tensile strength of glass material compared to jute material (Albahash and Ansari, 2017). This result is consistent with the study by $\mathrm{Hu}$ et al. (2010).

Concerning mean load $\left(P_{m}\right)$, as compared to the overall mean load result of nonhybrid with hybrid composite tube, the mean load for the pure composite of the corrugated tube made of bidirectional JRFP with three layers is the lower value (i.e., $P_{m}=$ $11.209 \mathrm{kN}$ ), while the mean load of hybrid of the corrugated tube made from (2-layer Jute + 1-layer glass) was $19.613 \mathrm{kN}$ as shown in Table 2. By reviewing Figure 5, it appears that the largest value of the average load contributes to obtaining the greatest energy absorption capacity, as it has been discussed with details in the next section of the research. This conclusion was consistent with the published report by Ghasemnejad et al. (2010). However, comparing the current experimental result by the Pareto chart as 


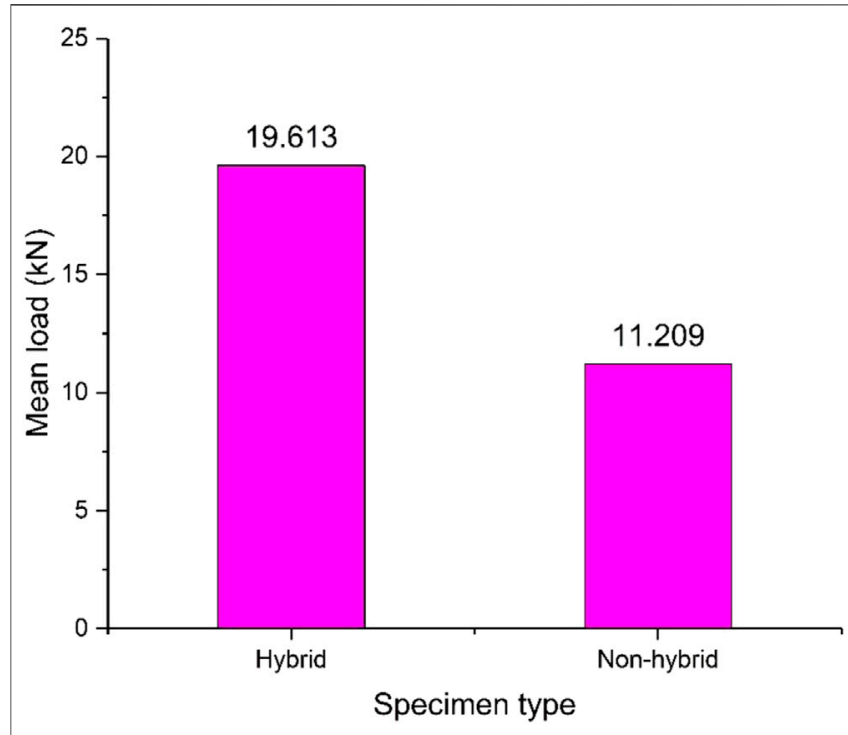

FIGURE 6 | A comparison of $P_{m}$ between hybrid and nonhybrid composite specimen.

depicted in Figure 6, it can be seen that the mean crush load $\left(P_{m}\right)$ of the hybrid with one layer of glass was higher than those of nonhybrid by about $43 \%$, which contributed with more stability as well.

For crushing efficiency $(n c)$, another significant indicator that needs to be taken into consideration in assessing the energy dissipation performance of the designed structure is the nc. It is calculated mathematically by dividing the average load over the maximum peak load, which is usually from zero to one. Therefore, the closer the efficiency is to a unit, it indicates that the performance is close to the ideal value (Sivagurunathan et al., 2018a). Figure 5 shows that the bigger crush efficiency value indicated stability and progressive collapsing during displacement under the crush loading test that usually yielded a higher $S E A$, in contrast to the catastrophic failure during crushing that shows a decrease in the value of $n c$. On the other hand, the high value of crushing efficiency occurs in the event of the slight difference between the peak and average load (Roslan et al., 2017). However, it is obvious that the larger and the best stability results were recorded by the hybrid (jute + glass) fibers compared to the nonhybrid specimens in this experiment as shown in Figure 7

\section{Hybrid Influence on Energy Absorption Characteristic}

The energy absorption, $E A$, represents the total work done during the uniaxial crush loading of a specimen, which is equal to the area between the crushing curve path and the $x$-axis. Therefore, the total absorbed energy is the sum of the areas of the crushing stages except the area of the compaction stage because of its small value compared to pre- and postcrushing phase (Mahdi and Sebaey, 2014b). As depicted above in Table 2 and Figure 8, the greatest energy absorption was noticed in the corrugated tube
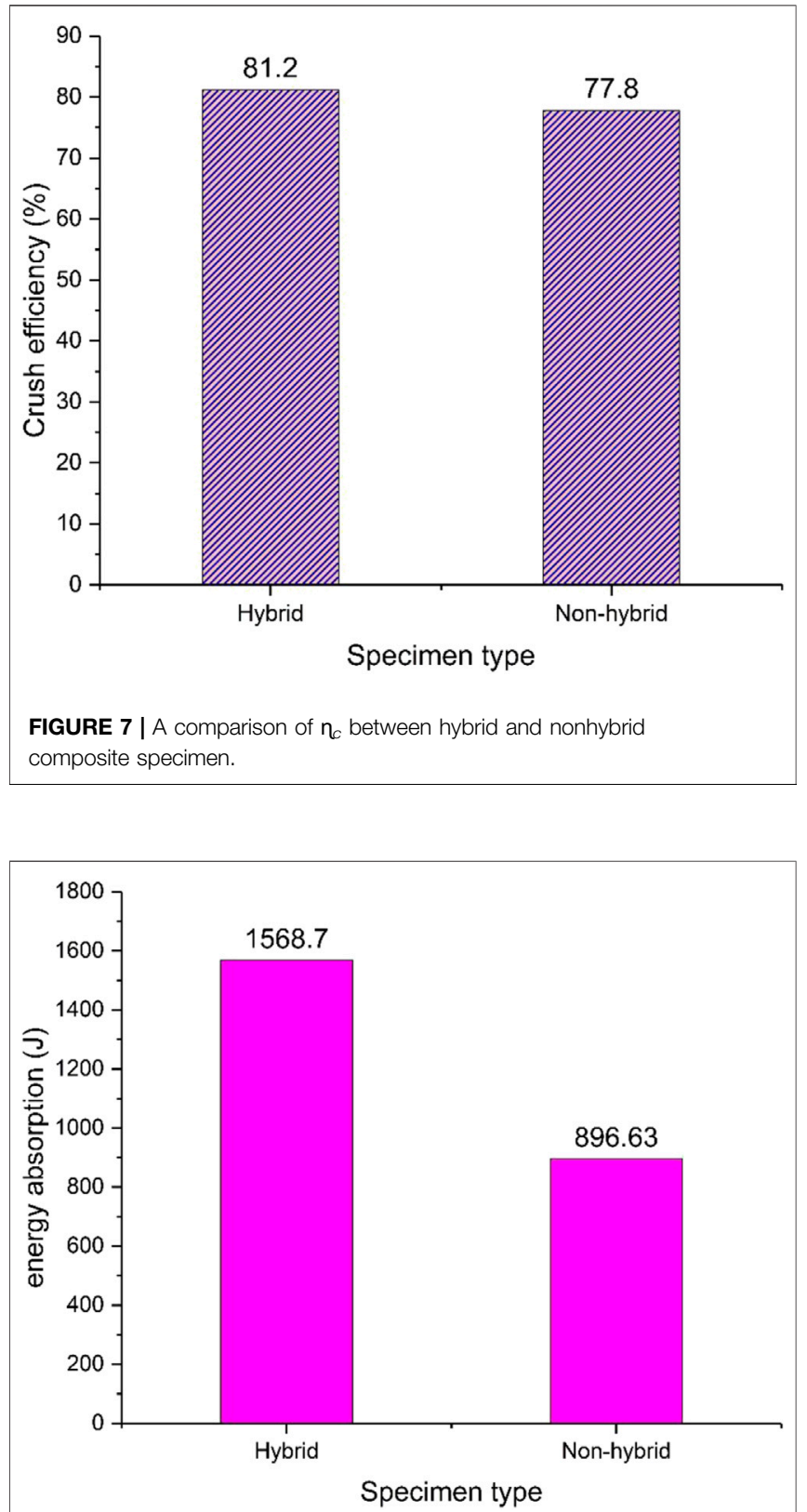

FIGURE 8 | A comparison of energy absorption between nonhybrid and -hybrid composite specimen.

with hybrid (two jute + one glass) fibers layers compared to the pure jute fibers epoxy composite, which attained $1.5687 \mathrm{~kJ}$. This cues that the hybridization composite, in case that low modulus fibers are combined with the high modulus fibers compared to each other, has a larger effect on the energy absorption capacity of the composite tubes. On the other hand, the flexural, tensile, and strength properties of jute fibers reinforced epoxy composites are improved by the enhancement of one layer of glass fibers in this composite, demonstrating the positive hybrid influence. The TEA by this hybrid mechanism was about 1.8 times larger than pure jute/epoxy composite specimen at the same geometry 


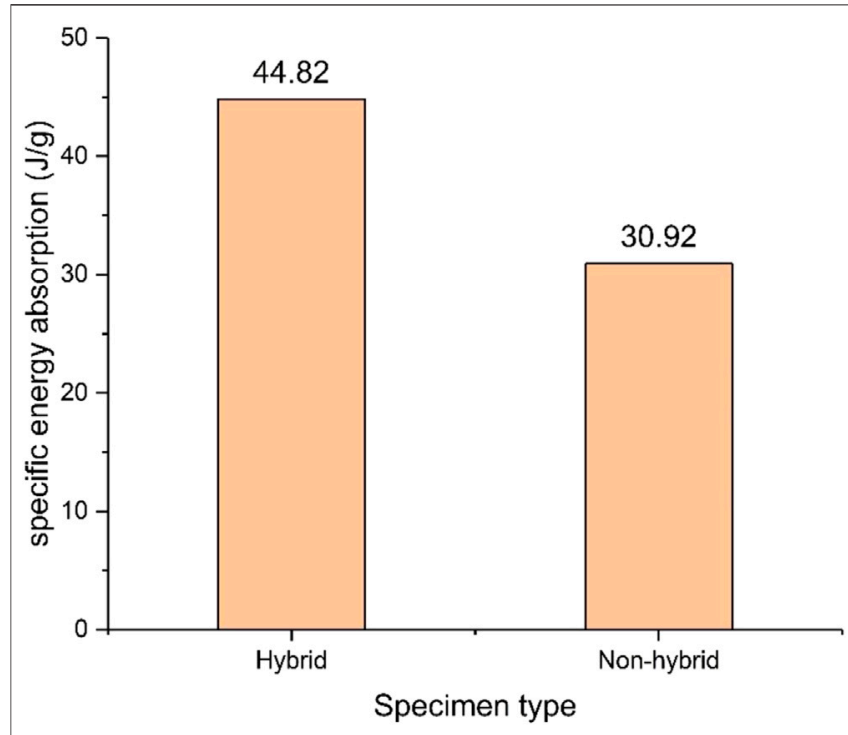

FIGURE 9 | A comparison of SEA between nonhybrid and hybrid composite specimen.

configuration. The same conclusion was reached by Reddy et al. (2016).

However, the energy absorption is a function that represents an area under the curve resulting from the computing of the applied load multiplied by the displacement of the crushed specimen, which depends on the area of the cross-section and the mass of the structure crushed (Mahdi and Sebaey, 2014a). Therefore, using the different cross-section and mass for each specimen might be misleading for the evaluation of the $E A$. For a realistic comparison, when assessing the energy absorbing ability of structures, it is necessary to use the specific absorbed energy, SEA, which represents the area under the loaddeformation curve divided by the mass of the specimen (Jimenez et al., 2000; Alkbir et al., 2014). Therefore, the SEA is defined as a significant factor to compare the TEA capabilities. From Figure 9, it is clear that a significant improvement in the ability to absorb energy can be found through the hybridization mechanism of different types of brittle fibers, taking into account optimization of the production cost. The SEA of the hybrid specimen was $44.82 \mathrm{~J} / \mathrm{g}$ which was about 1.45 times higher than the nonhybrid specimen used in the current study. Besides, it was about 5.24-9.64 and 2.1-5 times higher than square and circle of (two Jute + one glass) specimens, respectively, in the previous study by Albahash and Ansari (2017). This indicates that even though the same materials are used, the geometrical shape and dimension of the structure play a significant role in the effect of the energy absorption capability. On the other hand, the current result of SEA for the hybrid composite specimen is higher than the metal structure value mentioned in the comparison part (Table 3). Therefore, based on the test results, the energy absorption capacity of the composite structure could be improved by hybridization using reasonable fibers; this conclusion is matched as reported by Albahash and Ansari (2017) and Hu et al. (2010).

\section{Comparison With Previously Reported Works}

To assess the current results, they are compared with other previous works reports which were using different material and geometric shapes as shown in Table 3. However, because each work presented different geometrical shape and material, the evaluation of energy absorption (EA) might be misleading. Therefore, a more realistic comparison can be made using a specific energy absorption (SEA) which was taking into account the mass of materials.

From table 3, it can be seen that replacing one jute fiber layer by one layer of woven glass for corrugated tube achieved the highest SEA compared to natural, synthetic, and metallic materials. In addition, it exhibited more stability and less potential to buckle under a quasi-static crushing test, due to its failure in brittle mode with a progressive crushing. Thus, it can be considered that hybrid jute-glass/epoxy corrugated specimen is good choice to substitute the tubular metal, synthetic composite, and natural composite in terms of energy absorption capability.

TABLE 3 | Summarized current work and comparing the result with previous reported works.

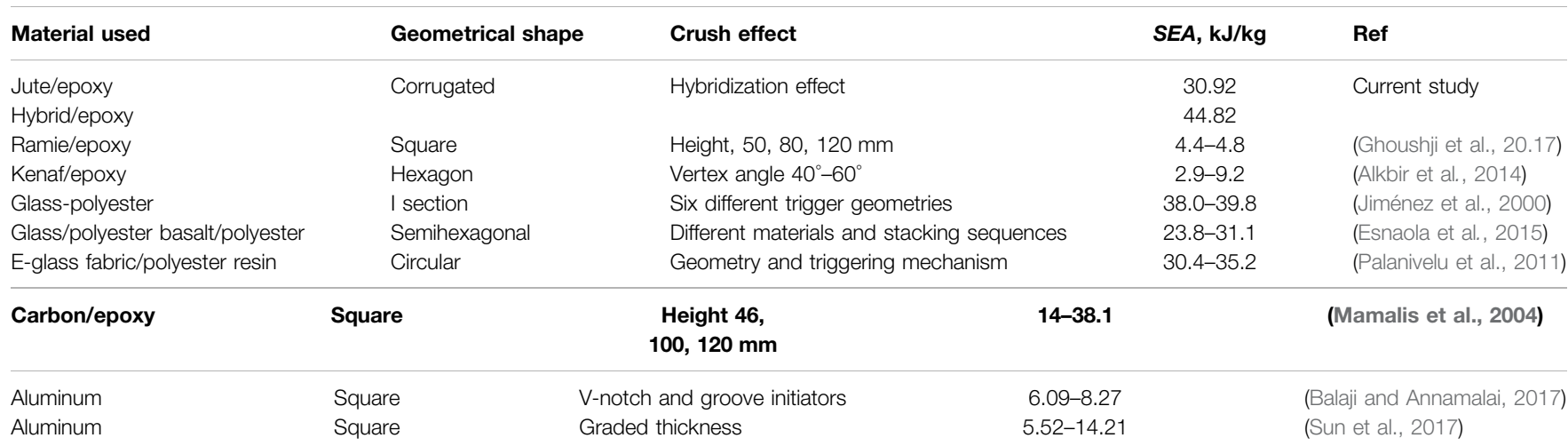




\section{CONCLUSION}

The hybrid composite tube based on jute and glass fiber was manufactured using epoxy resin. Composites with jute/epoxy were also prepared for purposes of comparison. However, for hybrid specimens, it can be concluded that using materials of low modulus fibers combined with the high modulus fibers compared to each other caused significant differences in the crashworthiness parameters and failure patterns of composite tubes. Based on the experimental results, the following can be drawn:

1. It was observed that the energy absorber performance of a corrugated hybrid composite tube with three layers was significantly improved by replacing one of three jute mat layers by glass mat layer in consideration of crashworthiness optimization. The hybrid specimen considered superior as it recorded the highest $P_{m}, E A, S E$, and $\eta_{c}$ values compared to nonhybrid specimens.

2. Hybridization is a good option in terms of finding a balance in the material properties, where the choice of fibers with high modulus contributes to the stiffness and load bearing, while the fibers with low modulus make the compound more damage tolerant, thus obtaining a design with specifications superior to both materials at a low cost.

3. The design of a hybrid fibers/epoxy specimen, in the tubes chosen for this research, has a $S E$ of $44.82 \mathrm{~J} / \mathrm{g}$ and a $\eta_{c}$ of $81.21 \%$, which is superior to conventional metallic energy absorber and it is closer to that of carbon and glass fibers reinforced polymers composites which are reported in the previous studies.

\section{REFERENCES}

Abdewi, E. F., Sulaiman, S., Hamouda, A. M. S., and Mahdi, E. (2006). Effect of geometry on the crushing behaviour of laminated corrugated composite tubes. J. Mater. Process. Technol. 172 (3), 394-399. doi:10.1016/j.jmatprotec.2005.07.017

Abdewi, E. F., Sulaiman, S., Hamouda, A. M. S., and Mahdi, E. (2008). Quasi-static axial and lateral crushing of radial corrugated composite tubes. Thin-Walled Struct. 46 (3), 320-332. doi:10.1016/j.tws.2007.07.018

Abosbaia, A. A. S., Mahdi, E., Hamouda, A. M. S., and Sahari, B. B. (2003). Quasistatic axial crushing of segmented and non-segmented composite tubes. Compos. Struct. 60 (3), 327-343. doi:10.1016/s0263-8223(02)00341-0

Al-Qrimli, H. F., Mahdi, F. A., Ismail, F. B., and Alzorqi, I. S. (2015). Thin-walled composite tubes using fillers subjected to quasistatic axial compression. IOP Conf. Ser.: Mater. Sci. and Eng., 78 (7), 1012024. doi:10.1088/1757-899X/78/1/ 012024

Albahash, Z. F., and Ansari, M. N. M. (2017). Investigation on energy absorption of natural and hybrid fiber under axial static crushing. Compos. Sci. Technol. 151, 52-61. doi:10.1016/j.compscitech.2017.07.028

Alkbir, M. F. M., Sapuan, S. M., Nuraini, A. A., and Ishak, M. R. (2014). Effect of geometry on crashworthiness parameters of natural kenaf fibre reinforced composite hexagonal tubes. Mater. Des. 60, 85-93. doi:10.1016/j.matdes. 2014.02.031

Balaji, G., and Annamalai, K. (2017). An experimental and numerical scrutiny of crashworthiness variables for square column with $\mathrm{V}$-notch and groove initiators under quasi-static loading. Cogent Eng. 4 (1), 1364118. doi:10. 1080/23311916.2017.1364118

Boria, S., Scattina, A., and Belingardi, G. (2018). Axial crushing of metal-composite hybrid tubes: experimental analysis. Procedia Struct. Integrity 8, 102-117. doi:10.1016/j.prostr.2017.12.012

\section{DATA AVAILABILITY STATEMENT}

The raw data supporting the conclusions of this article will be made available by the authors, without undue reservation.

\section{AUTHOR CONTRIBUTIONS}

$\mathrm{SH}$ performed experiments, investigation, methodology, and data analysis and drafted the manuscript. AI performed project supervision, funding acquisition, formal analysis, and drafting the manuscript. YY performed methodology and experimental analyses and wrote and reviewed and edited the manuscript. AA reviewed and edited the manuscript. MS reviewed funding acquisition and edited the manuscript. All authors contributed to the article and approved the submitted version.

\section{ACKNOWLEDGMENTS}

The authors gratefully thank the Faculty of Mechanical and Manufacturing Engineering, University Tun Hussein Onn Malaysia (UTHM), and Centre for Composites, (UTeM) Universiti Teknikal Malaysia Melaka, so much for their support in this research, as well as the Ministry of Construction, Housing and Public Municipalities/Al-Muthanna Water Directorate, Iraq, for their financial and moral support in accomplishing this work.

Esnaola, A., Ulacia, I., Aretxabaleta, L., Aurrekoetxea, J., and Gallego, I. (2015). Quasi-static crush energy absorption capability of E-glass/polyester and hybrid E-glass-basalt/polyester composite structures. Mater. Des. 76, 18-25. doi:10. 1016/j.matdes.2015.03.044

Ghasemnejad, H., Hadavinia, H., and Aboutorabi, A. (2010). Effect of delamination failure in crashworthiness analysis of hybrid composite box structures. Mater. Des. 31 (3), 1105-1116. doi:10.1016/j.matdes.2009.09.043

Ghoushji, M. J., Eshkoor, R. A., Zulkifli, R., Sulong, A. B., Abdullah, S., and Azhari, C. H. (2017). Energy absorption capability of axially compressed woven natural ramie/green epoxy square composite tubes. J. Reinf. Plast. Compos. 36 (14), 1028-1037. doi:10.1177/0731684417700482

Hu, D. Y., Luo, M., and Yang, J. L. (2010). Experimental study on crushing characteristics of brittle fibre/epoxy hybrid composite tubes. Int. J. Crashworthiness 15 (4), 401-412. doi:10.1080/13588261003647402

Ismail, A. E. (2016). Crushing mechanisms of cylindrical winding kenaf fiber reinforced composites. Jurnal Teknologi 78 (6), 45-50. doi:10.11113/jt.v78. 5258

Ismail, A. E., Awang, M. K., and Sa'at, M. H. (2007). Tensile strength of natural fiber reinforced polyester composite. AIP Conf. Proc. 909, 174-179. doi:10. 1063/1.2739848

Ismail, A. E., and Che Abdul Aziz, M. A. (2015). IOP Conf. Ser. Mater. Sci. Eng. 100 (1), 012037. doi:10.1088/1757-899x/100/1/012037

Ismail, A. E., and Mohd Tobi, A. L. (2016). Axial energy absorption of woven kenaf fiber reinforced composites. ARPN J. Eng. Appl. Sci. 11 (14), 8668-8672.

Jimenez, M. A., Miravete, A., Larrode, E., and Revuelta, D. (2000). Effect of trigger geometry on energy absorption in composite profiles. Compos. Struct. 48 (1-3), 107-111. doi:10.1016/s0263-8223(99)00081-1

Lau, S. T. W., Said, M. R., and Yaakob, M. Y. (2012). On the effect of geometrical designs and failure modes in composite axial crushing: a literature review. Compos. Struct. 94 (3), 803-812. doi:10.1016/j.compstruct.2011.09.013 
Mahdi, E., Hamouda, A. M. S., Sahari, B. B., and Khalid, Y. A. (2003a). Experimental quasi-static axial crushing of cone-tube-cone composite system. Compos. B Eng. 34 (3), 285-302. doi:10.1016/s1359-8368(02)00102-6

Mahdi, E., Hamouda, A. M. S., Sahari, B. B., and Khalid, Y. A. (2003b). On the collapse of cotton/epoxy tubes under axial static loading. Appl. Compos. Mater. 10 (2), 67-84. doi:10.1023/a:1022890104728

Mahdi, E., and Sebaey, T. A. (2014a). An experimental investigation into crushing behavior of radially stiffened GFRP composite tubes. Thin-Walled Struct. 76, 8-13. doi:10.1016/j.tws.2013.10.018

Mahdi, E., and Sebaey, T. A. (2014b). Crushing behavior of hybrid hexagonal/ octagonal cellular composite system: aramid/carbon hybrid composite. Mater. Des. 63, 6-13. doi:10.1016/j.matdes.2014.06.001

Mamalis, A. G., Manolakos, D. E., Ioannidis, M. B., and Papapostolou, D. P. (2004). Crashworthy characteristics of axially statically compressed thin-walled square CFRP composite tubes: experimental. Compos. Struct. 63 (3-4), 347-360. doi:10. 1016/s0263-8223(03)00183-1

McGregor, C., Vaziri, R., Poursartip, A., and Xiao, X. (2016). Axial crushing of triaxially braided composite tubes at quasi-static and dynamic rates. Compos. Struct. 157, 197-206. doi:10.1016/j.compstruct.2016.08.035

Mishra, V., and Biswas, S. (2013). Physical and mechanical properties of bidirectional jute fiber epoxy composites. Procedia engineering 51, 561-566. doi:10.1016/j.proeng.2013.01.079

Okubo, K., Fujii, T., and Yamamoto, Y. (2004). Development of bamboo-based polymer composites and their mechanical properties. Compos. Appl. Sci. Manuf. 35 (3), 377-383. doi:10.1016/j.compositesa.2003.09.017

Palanivelu, S., Paepegem, W. V., Degrieck, J., Vantomme, J., Kakogiannis, D., Ackeren, J. V., et al. (2011). Crushing and energy absorption performance of different geometrical shapes of small-scale glass/polyester composite tubes under quasi-static loading conditions. Compos. Struct. 93 (2), 992-1007. doi:10.1016/j.compstruct.2010.06.021

Palanivelu, S., Van Paepegem, W., Degrieck, J., Kakogiannis, D., Van Ackeren, J., Van Hemelrijck, D., et al. (2010). Parametric study of crushing parameters and failure patterns of pultruded composite tubes using cohesive elements and seam, Part I: central delamination and triggering modelling. Polym. Test. 29 (6), 729-741. doi:10.1016/j.polymertesting.2010.05.010

Rabiee, A., and Ghasemnejad, H. (2017). Progressive crushing of polymer matrix composite tubular structures: review. Open J. Compos. Mat. 7 (1), 14-48. doi:10. 4236/ojcm.2017.71002

Raghavendra, G., Ojha, S., Acharya, S., and Pal, S. (2014). Jute fiber reinforced epoxy composites and comparison with the glass and neat epoxy composites. J. Compos. Mater. 48 (20), 2537-2547. doi:10.1177/0021998313499955
Reddy, T. S., Subba Reddy, P. R., and Madhu, V. (2016). Influence of hybridization on the performance of glass composites under low and high velocity impact. Adv. Mater. Lett. 7 (6), 491-496. doi:10.5185/amlett.2016.6316

Roslan, M. N., Yahya, M. Y., Ahmad, Z., and Azrin Hani, A. R. (2017). Energy absorption behaviour of braided basalt composite tube. Adv. Compos. Mater. 27 (5), 467-481. doi:10.1080/09243046.2017.1405604

Said, M. R., Lau, S. T., and Yaakob, M. Y. (2017). Quasi static axial crushing of kenaf fibre reinforced epoxy composite fabricated by VARTM method. ARPN J. Eng. Appl. Sci 12, 4804-4808.

Shibata, S., Cao, Y., and Fukumoto, I. (2005). Press forming of short natural fiberreinforced biodegradable resin: effects of fiber volume and length on flexural properties. Polym. Test. 24 (8), 1005-1011. doi:10.1016/j.polymertesting.2005. 07.012

Sivagurunathan, R., Lau Tze Way, S., Sivagurunathan, L., and Yaakob, M. Y. (2018a). The effects of triggering mechanisms on the energy absorption capability of circular jute/epoxy composite tubes under quasi-static axial loading. Appl. Compos. Mater. 25 (6), 1401-1417. doi:10.1007/s10443-0189673-5

Sivagurunathan, R., Way, S. L. T., Sivagurunathan, L., and Yaakob, M. Y. (2018b). Effects of triggering mechanisms on the crashworthiness characteristics of square woven jute/epoxy composite tubes. J. Reinf. Plast. Compos. 37 (12), 824-840. doi:10.1177/0731684418763218

Summerscales, J., Dissanayake, N. P. J., Virk, A. S., and Hall, W. (2010). A review of bast fibres and their composites. Part 1 - fibres as reinforcements. Compos. Appl. Sci. Manuf. 41 (10), 1329-1335. doi:10.1016/j.compositesa. 2010.06.001

Sun, G., Pang, T., Xu, C., Zheng, G., and Song, J. (2017). Energy absorption mechanics for variable thickness thin-walled structures. Thin-Walled Struct. 118, 214-228. doi:10.1016/j.tws.2017.04.004

Conflict of Interest: The authors declare that the research was conducted in the absence of any commercial or financial relationships that could be construed as a potential conflict of interest.

Copyright (c) 2021 Salim Hamza, Ismail, Yuhazri, Ariffin and Hameed Sultan. This is an open-access article distributed under the terms of the Creative Commons Attribution License (CC BY). The use, distribution or reproduction in other forums is permitted, provided the original author(s) and the copyright owner(s) are credited and that the original publication in this journal is cited, in accordance with accepted academic practice. No use, distribution or reproduction is permitted which does not comply with these terms. 